\title{
Conditional threats of suicide and jail suicide
}

\begin{abstract}
This paper presents a case study involving a male who made a conditional threat of suicide and subsequently took his own life in a county jail. Although he was assessed for suicidality and a monitoring plan was implemented, he was not placed on suicide watch. He eventually suicided and an 8th Amendment action were commenced. For reasons discussed in this case report, the matter was dismissed.
\end{abstract}

Keywords: jail suicide, threats of suicide, malingering, corrections, protective factors, mental health

\author{
Volume 5 Issue 4 - 2017 \\ Dennis M Savard,' Daniel B Kennedy² \\ 'Saginaw Valley State University and Forensic Criminology \\ Consultants, USA \\ ${ }^{2}$ Oakland University and Forensic Criminology Associates, USA
}

Correspondence: Daniel B Kennedy, Oakland University and Forensic Criminology Associates, USA,

Email danielbkennedy@comcast.net

Received: September 07, 2017 | Published: October 02, 2017

\section{Introduction}

Suicide in the United States has been identified as the 10th leading cause of death with approximately 44,000 individuals intentionally taking their lives every year and for each suicide, an additional 25 individuals make attempts on their lives. In addition to the obvious loss of life and the psychological pain family and friends experience in the aftermath of suicide, the United States incurs $\$ 51$ billion annually because of suicide. ${ }^{1}$ Suicide has not only been identified as a problem in free society, but has also been linked to jails and prisons. Studies have found higher suicide rates in jails, but the validity of these studies can be challenged based on questionable data comparisons to the general population and the methods used to calculate suicide rates. Compounding the issue of jail suicide is the prevalence of inmates who have a mental illness, but foreseeing an inmate's suicide can be problematic because of a low base rate problem and false positives. Because custody suicide is a low base rate phenomenon, there is always the risk of identifying an inmate as suicidal when in fact he or she is not. This false positive problem leads to the medical isolation and possible deterioration of inmates who possess certain risk factors but are not suicidal. Hence, inmates should not be placed on suicide watch with excessive alacrity. This paper presents the case of a young male who committed suicide in a county jail, a tragedy complicated by the difficulty in interpreting the nature of the threats he made before finally taking his own life.

\section{Case presentation}

While in the custody of a jail located in a Midwestern state, a young man committed suicide by lacerating his neck. During the early morning hours, the subject cut himself repeatedly even as corrections officers struggled with him to stop his violent, suicidal actions. He was disarmed, restrained, and treated by jail and EMS personnel but was ultimately pronounced dead at a nearby hospital. Upon initial admittance to the jail, he was evaluated for possible suicidality by a jail mental health worker and cleared for general population approximately three days after his initial incarceration. His incarceration at the jail had been relatively uneventful until about seven months when family members reported to jail staff that he had threatened suicide if his criminal charges were to go forward to trial. In response to this conditional threat, the jail mental health worker prepared an elaborate precautionary plan revolving around the subject's anticipated court dates. The worker did not, however, place him in a segregated cell under suicide watch.
Because the jail mental health worker conducted an indirect assessment of the subject (by observation) rather than a direct assessment (by interview), the plaintiff lawyer argued this constituted an 8th Amendment violation of the subject's rights to be free from "cruel and usual punishment," by denying him competent medical/ psychiatric care. Furthermore, the plaintiff argued that, among other charges, the jail mental health worker actually drew the inference that there was an excessive risk of harm to the subject and that the jail mental health worker consciously disregarded that risk. ${ }^{1}$ As we will explain more fully below, it was our opinion that the jail mental health worker's discretionary actions in this matter were within reasonable parameters of custody-related mental health practices, ${ }^{2}$ particularly given the totality of the circumstances.

\section{Foundational materials}

Before forming any opinions in this matter as forensic criminologists, we reviewed the civil complaint, current court decisions concerning custody suicide, jail activity logs, corrections officers' incident reports, booking and screening documents, mental health notes concerning the subject's letters to and from the family members, court documents, and miscellaneous other documents. We also reviewed appropriate current professional literature and studied several depositions. A site-visit of the jail was completed and brief interviews of jail staff were conducted.

\section{Case analysis}

Health care, including mental health care, can be quite challenging in a custody setting compared to a "free world" setting. Inmates of all stripes have been described as "difficult, manipulative, aggressive, and demanding". ${ }^{2}$ Malingering is used for secondary gain and, in fact, the DSM-IV-TR and the DSM-V both discuss the possibilities of malingering in a forensic setting (i.e., jail or prison). ${ }^{3}$ Notwithstanding the possibility of inmate malingering for secondary benefit (e.g., hospitalization in a more comfortable setting with improved chances

\footnotetext{
${ }^{1}$ These requirements stem from Estelle V Gamble, Farmer V Brennan as explained to correctional practitioners by legal scholars, i.e., R. del Carmen, S. Ritter and B. Witt, Briefs of Leading Cases in Corrections (4th edn). (Anderson Publishing, 2005), pp. 97-99 and 115-117.

${ }^{2}$ We are aware of no correctional "ministerial" requirements that would dictate that the jail mental health worker should have reacted with some sort of specific protocol, especially given the nature of the subject's conditional threats. Further commentary on the recent U.S. Supreme Court case of Taylor v. Barkes (2015) may bear out my thinking in this matter.
} 
of escape) and the inherent impossibility of predicting suicide on an individual level even in a free-world population, ${ }^{3}$ skilled mental health workers do not dismiss the possibility that malingerers can, in fact, be suicidal as well. Hence, mental health workers must not dismiss an inmate's possible suicidality as mere malingering.

Note that the jail mental health worker did no such thing and, in fact, laid out a detailed monitoring plan centeredaround the subject's three upcoming court dates, along with a plan to conduct separate mental health assessments prior to each of those court dates. Thus, it would be completely erroneous to argue that the jail mental health worker consciously disregarded a serious medical need, thus putting the subject at risk. He did not. Plaintiff can only argue that the jail mental health worker's response and prevention plan was so woefully and totally inept as to constitute virtually no response at all. Neither is this the case. There are a number of considerations which clarify the reasonable nature of the jail mental health worker's response to future possibilities of self-injury by the subject, particularly given the totality of circumstances surrounding this complex matter. The subject is reputed to have threatened suicide if his cases went to trial. This type of threat is known as a "conditional" threat ${ }^{4}$ and is often employed to manipulate people into taking some action deemed beneficial by the threatener. ${ }^{5}$ In actuality, individuals who are "contingently" suicidal (i.e., make conditional threats) are far less likely to commit suicide than those who are truly suicidal. ${ }^{4}$ Also, please note that corrections officers reported that no signs of suicidality had been manifested by the subject since his initial screening some ten months prior to his death. In one Texas study, two-thirds of jail suicides took place within a month of admission to the jail. ${ }^{5}$ Clearly, the greatest risk of inmate suicide is within the first days and weeks of incarceration, and the subject had long since passed through that period with no obvious adverse effects. Given that no other indicators of suicide were present, except for conditional threats made to family members only and given the iatrogenic nature of interpersonal isolation associated with a suicide watch, the decision to leave this subject in a regular cell was not a violation of his $8^{\text {th }}$ Amendment rights.

\section{Conclusion}

Given the above circumstances, there is no reason to believe that the subject was at imminent risk for suicide at the time of his death. He had not been abandoned by his family and was being emotionally

${ }^{3}$ Due to the low base rate of suicide and the problem of false positives, it is generally not possible to effectively predict suicide at the individual level. This is a widely known conclusion. For further discussion, see A. Pokorny, "Prediction of Suicide in Psychiatric Patients," Archives of General Psychiatry 40 (1983): 249-257; R. Maris, "Forensic Suicidology: Litigation of Suicide Cases and Equivocal Deaths," pps. 235-252 in B. Bongar (Ed.) Suicide: Guidelines for Assessment, Management, and Treatment (Oxford University Press, 1992); D. Hughes, "Can the Clinician Predict Suicide?" Psychiatric Services 46 (1995): 449-451.

${ }^{4} \mathrm{~A}$ conditional threat is distinguished from a direct threat, an indirect threat, and a veiled threat. See FBI behavioral scientist M. E. O'Toole, The School Shooter: A Threat Assessment Perspective (Quantico, Diane Publishing, 2000). For a more through analysis of threats routinely encountered by criminal justice practitioners, see J. McCann, Threats in Schools: A Practical Guide for Managing Violence (New York: The Haworth Press, 2002, p. 21).

${ }^{5}$ L. Reccoppa, "Mentally Ill or Malingering? Clues Cast Doubt," Current Psychiatry 8 (2009): 110. See, also, B. Blasko et al., "Suicide Risk Assessment in Jails," Journal of Forensic Psychology Practice 8 (2008): "Some inmates may feign or malinger suicidal intent or behavior in an attempt to manipulate their environment or derive secondary gains, making it difficult to identify genuine disorders from feigned disorders." supported by his mother and brother (protective factors). He displayed no signs or symptoms of suicidality to corrections officers or other inmates that we know of. To place him in a suicide cell because of a hearsay conditional threat, given the circumstances cited above, could actually have been perceived as more likely to be harmful than helpful to the subject. Inmates on suicide watch are confined to a bare cell, made to remain naked in front of a camera except for a suicide gown, denied recreational activities, and deprived of social contact with other prisoners. These segregation conditions are believed to be detrimental to an inmate's mental health ${ }^{6}$ and have been cautioned against by at least one judicial commentator. ${ }^{7}$

Finally, we address two other matters pertaining to proximate cause. Even had the jail mental worker responded to the subject's conditional threat with a direct rather than an indirect assessment, would the subject have admitted to suicidal ideation and or intent knowing this would result in being placed on suicide watch in a specially designated suicide-resistant cell? Given the obvious commitment the subject had to ending his life, it is likely he would have denied any intention of harming himself ${ }^{6}$ just as he had done ten months prior during his first assessment. This denial of suicide ideation and planning is common among suicidal inmates who know the results of admitting to suicidality. ${ }^{7}$ In one study of veterans who had committed suicide, 85 percent had denied suicidality when formally assessed between 0-7 days prior to death by suicide. ${ }^{8}$ Secondly, criticism has been directed at sheriff's personnel because the subject was allowed use of a razor with which to shave. Even had the subject been denied access to a razor, in spite of the fact he was not on suicide watch, likely he would have simply used some form of ligature fashioned from clothing or bedding. In fact, the overwhelming majority (93 percent) of inmates who committed suicide chose asphyxiation by hanging as the method. ${ }^{9}$ Keeping a razor from the subject would not have prevented him from killing himself. Because a large majority of suicides in jails involve the use of a ligature, ${ }^{10,11}$ this case is atypical in that the decedent suicided by slashing his throat with a razor. Even though the authors believe jail personnel took the appropriate steps when responding to the subject's conditional threat of suicide, his case illustrates the difficulty of forecasting suicide.

\section{Acknowledgments}

None.

\section{Conflicts of interest}

Author declares that there is no conflict of interest.

\section{Funding}

None.

\section{References}

\section{1. https://afsp.org/about-suicide/suicide-statistics/}

2. Flanagan N, Flanagan T. Correctional Nurses' Perceptions of Their Role, Training Requirements, and Prisoner Health Care Needs. Journal of Correctional Health Care. 2001;8(1):75-76.

${ }^{6}$ Federal District Court Judge Sharp wrote in Strickler v. McCord (2004) that "a duty to take the maximum precautions for all inmates with any level of suicide risk would make life miserable for any persons at a low level of risk for suicide (p. 28)."

${ }^{7}$ Recall how the corrections officers had to struggle with the subject to try to stop him from slashing at his neck as he implored them to "let him go." 
3. Diagnostic and Statistical Manual of Mental Disorders. 5th ed, USA: American Psychiatric Association; 2013. p. 726-727.

4. Lambert M. Seven-Year Outcomes of Patients Evaluated for Suicidality. Psychiatric Services. 2002;53(1):92-94.

5. Dillon D. A Portrait of Suicides in Texas Jails: Who is at Risk and How do we Stopit? LBJ Journal of Public Affairs. 2013;21:51-67.

6. Metzner J. Mental Health Considerations for Segregated Inmates. Correct Care Fall. 1997;14-15.

7. Felthous AR. Does Isolation Cause Jail Suicides? J Am Acad Psychiatry Law. 1997;25(3):285-294.
8. Tartaro C. What is Obvious? Federal Courts' Interpretation of the Knowledge Requirement in Post-Farmer v. Brennan Custodial Suicide Cases. The Prison Journal. 2015;95(1):23-42.

9. Smith EG, Kim HM, Ganoczy D, et al. Suicide Risk Assessment Received Prior to Suicide Death by Veterans Health Administration Patients With a History of Depression. Journal of Clinical Psychiatry. 2013;74(3):226-232.

10. Hayes L. National Study of Jail Suicide: 20 Years Late. Journal of Correctional Health Care. 2012;18(1):233-245.

11. Bardale RV, Dixit PG. Suicide Behind Bars: A 10-Year Retrospective Study. Indian Journal of Psychiatry. 2015;57(1):81-84. 